University of Wollongong

Research Online

Faculty of Engineering and Information

Faculty of Engineering and Information

Sciences - Papers: Part A

Sciences

$1-1-2006$

\title{
Black start with DFIG based distributed generation after major emergencies
}

\author{
M Aktarujjaman \\ University of Tasmania \\ Kashem M. Muttaqi \\ University of Tasmania, kashem@uow.edu.au \\ Michael Negnevitsky \\ University of Tasmania, michael.negnevitsky@utas.edu.au \\ Gerard Ledwich \\ Queensland University of Technology, g.ledwich@qut.edu.au
}

Follow this and additional works at: https://ro.uow.edu.au/eispapers

Part of the Engineering Commons, and the Science and Technology Studies Commons

Research Online is the open access institutional repository for the University of Wollongong. For further information contact the UOW Library: research-pubs@uow.edu.au 


\title{
Black start with DFIG based distributed generation after major emergencies
}

\begin{abstract}
Grid connected distributed generation (DG) increases reliability and additional benefits for consumers as well as utilities. The stable and reliable operation of a power system is necessary after major emergencies (or blackouts) following a major system event. Distributed generation may be capable of black start and contribute to fast restoration process at medium to low voltage level. A large scale voltage and frequency excursions may occur during the process of black start with distributed generation due to low inertia and intermittency in power generation. Energy storage integrated with DG can absorb initial impact of central generation and ensure smooth load pickup during the restoration of a system. In this paper, the process of black start with a doubly fed induction generator (DFIG) based wind turbine is addressed and energy storage in DC link of DFIG is used for fast restoration after blackout. A control system has been developed for the process of black-start with DFIG. A sequence of actions for black start procedure is presented and tested.
\end{abstract}

\section{Keywords}

after, major, generation, start, distributed, black, dfig, emergencies

Disciplines

Engineering | Science and Technology Studies

\section{Publication Details}

M. Aktarujjaman, K. A. Kashem, M. Negnevitsky \& G. Ledwich, "Black start with DFIG based distributed generation after major emergencies," in IEEE International Conference on Power Electronics, Drives and Energy Systems (PEDES 2006), 2006, pp. 1-6. 


\section{Loading Capabilities Assessment of Power Transmission Lines}

ARTICLE

CITATION

1

3 AUTHORS, INCLUDING:

Michael Negnevitsky

University of Tasmania

195 PUBLICATIONS 2,023 CITATIONS

SEE PROFILE
DOWNLOADS

54

VIEWS

132
Kashem M. Muttaqi

University of Wollongong

110 PUBLICATIONS 1,031 CITATIONS

SEE PROFILE 


\title{
Loading Capabilities Assessment of Power Transmission Lines
}

\author{
Poh Tiew Hu, Michael Negnevitsky and Mohammad A. Kashem \\ School Of Engineering \\ University Of Tasmania \\ Hobart Australia \\ E-mail: ptjhu@postoffice.utas.edu.au
}

\begin{abstract}
This paper reviews the factors that affect the loading capabilities of the transmission line over the short duration. The paper demonstrates how to determine the impact of various parameters on the permissible loading of bare conductors of a power transmission line. Methods for calculating these factors are presented. A sample of a practical application is also included in order to show how these factors affect the loading capabilities of a transmission line.
\end{abstract}

Index Terms- Loading Capabilities Assessment, Heat Equation, Heat Gain, Heat Loss, Conductor Temperature.

\section{$1 \quad$ INTRODUCTION}

Due to increasing demands, transmission capacities currently are close to their limits. As building new transmission lines is expensive, there is a need for increasing the loading of existing transmission lines. This paper considers loading capabilities of a power transmission line.

The maximum loading capabilities of a long power transmission line can be determined by considering the system stability, economic energy losses or permissible voltage regulation [11]. On the other hand, the maximum loading capabilities for short power transmission lines can be determined by the thermal limit of the conductors, which determine the maximum sag, and the time distribution of conductor temperature [1]. The conductor temperature should be maintained within the safety limit. The ground conductor clearance consideration has often been used because it gives the lower limit. Maximum permissible temperature results in greatest permissible sag and also allows a maximum loss of tension strength by reducing the conductor life.

In Australia, maximum temperature for normal operation varies from 65 to $85{ }^{\circ} \mathrm{C}$ [1]. The conductor temperature depends on the load current, the electrical and thermal characteristic of conductor and atmospheric parameters such as wind velocity, sky condition, position of sun and others factors. The relationship between these parameters is known as heat equation. In this paper, heat equation will be examined in details under normal operation and fault current operation.

\section{THE HEAT EQUATION}

Conductor energy losses are caused by heat to the surrounding atmosphere. By considering the steady-state rating of the conductor, the following heat equation is applied [1]:

$P_{J}+P_{M}+P_{S}=P_{c o n}+P_{R}+P_{W}$

where $P_{J}, P_{M}$ and $P_{S}$ are the heat gains per unit length and per unit time by joule heating, magnetic heating and solar isolation respectively, and $P_{c o n}, P_{R}$ and $P_{W}$ are the heat losses per unit length and per unit time by convection, radiation and evaporation respectively. Heating and cooling due to the electrical corona [2] are neglected because this phenomenon is too complex and could occurs randomly. Evaporation term can also be neglected because it only occurs randomly. But in order to demonstrate the effect of water on the cooling of the conductor, it will be examined here.

\section{THE HEAT GAINS}

In this section, heat gain caused by joule heating $\left(P_{J}\right)$, magnetic heating $\left(P_{M}\right)$ and solar isolation $\left(P_{S}\right)$ will be studied in details.

\subsection{Joule Heating $\left(P_{J}\right)$}

Assuming that conductor is a cylinder, the Joule heat input is obtained as $[1,3]$ :

$P_{J}=k_{j} I^{2} R_{d c}\left[1+\alpha_{0}\left(T_{s}+\Delta T / 2\right)\right]$

where $I$ is the effective current (r.m.s), $R_{d c}$ is the dc resistance per unit length at $0^{\circ} \mathrm{C}, T s$ is the conductor surface temperature and $\Delta T$ is the temperature difference between core and surface of conductor and it is found from [3]:

$\Delta T \cong \frac{P_{J}}{2 \pi \lambda}\left[\frac{1}{2}-\frac{2 D_{C}{ }^{2}}{D_{S}{ }^{2}-D_{C}{ }^{2}} \ln \frac{D_{S}}{D_{C}}\right]$

where $\lambda$ is the effective thermal conductivity, and $D_{S}$ and $D_{C}$ are the diameter of the surface and core of conductor respectively. If the conductor is homogeneous, than $D_{C}=0$. 
The factor $k_{j}$ accounts for increase of resistance due to skin and proximity effects, eddy currents and hysteresis. With direct current, $k_{j}=1 . \alpha_{0}$ is the temperature coefficient between $0^{\circ} \mathrm{C}$ mean temperature of conductor.

\subsection{Magnetic Heating $\left(P_{M}\right)$}

The power gain due to magnetic viscosity varies with the frequency $f$ and with the square of the peak magnetic field strength $\mathrm{H}_{\mathrm{m}}$. At power frequency, magnetic field strengths up to $5 \mathrm{kA} / \mathrm{m}$ are negligible.

The hysteresis heat gain $P_{H}$ resulting from the movement of the magnetic domain walls in the cyclic field depends on magnetic induction $B_{m}$, temperature of steel wire $T_{c}$ and frequency $f$. This can be expressed by the following equation [4]:

$P_{H}=3.4 \times 10^{3} \exp \left(-2.3 \times 10^{-3} T_{C}\right) A_{C} f B_{m}^{1.68}$

where $A c$ is the steel wire cross-sectional area. The magnetic field strength for a conductor with $n_{t}$ layers of non-ferrous wires having alternative directions of lay is given by

$H_{m}=\sqrt{2} \sum_{n=1}^{n_{t}}\left[(-1)^{n+1} w_{n} I_{n} / s_{n}\right]$

where $\mathrm{w}_{\mathrm{n}}$ is the fraction of the layer current $I_{n}$ which flows helically around the steel core, and $s_{n}$ is the lay length of the wires in layer $\mathrm{n}$. The total heat gain $P_{M}$ due to the power loss in steel core is given by

$P_{M}=P_{e}+P_{H}$

where $P_{H}$ is usually 2 to 5 times $P_{e}$. The experimentally determined relationship for the above steel wire at $50 \mathrm{~Hz}$ is [5]:

$P_{M}=4.9 \times 10^{6} d^{1 / 2} A B_{m}^{1.82} \exp \left(-2.5 \times 10^{-3} T_{C}\right)$

where $d$ is the steel wire diameter.

\section{3. $\quad$ Solar Heating $\left(\boldsymbol{P}_{S}\right)$}

There will be additional heat gain by solar irradiation if the conductor is exposed outdoor or direct under the sun. It all depends on the absorptance of the conductor surface, total irradiance, angle of incidence between solar beam and the axis of the conductor, conductor projected area and also ground reflectance.

For isotropic diffuse sky radiation, total solar heat received by unit length of the conductor is given by [6]:

$$
P_{S}=a D I_{S}=a D\left(\left(1+\frac{\pi F}{2}\right) I_{d i r}+(1+F) \pi \frac{I_{\text {diff }}}{2}\right)
$$

Currently in Australian practice [6, 7], the value of 1000 $\mathrm{W} / \mathrm{m}^{2}\left(93 \mathrm{~W} / \mathrm{ft}^{2}\right)$ for direct solar radiation and $100 \mathrm{~W} / \mathrm{m}^{2}$ $\left(70 \mathrm{~W} / \mathrm{ft}^{2}\right)$ for diffuse solar radiation are chosen as the appropriate conditions throughout Australia for summer and winter noon conditions. Also it is assumed that under clear sky condition, diffuse radiation, $I_{d i f f}$, is $10 \%$ of the direct solar radiation, $I_{d i r}$.

$F$ is the albedo of the ground, and has a value of 0.2 for soil, grass and crops. Albedo values for other conditions of the ground are shown in table 1 .
Table 1:Albedo Value for different ground conditions

\begin{tabular}{|l|l|}
\hline Ground Condition & Albedo Value \\
\hline Water & 0.05 \\
\hline Forest & 0.1 \\
\hline Urban areas & 0.15 \\
\hline Sand & 0.3 \\
\hline Ice & $0.4-0.6$ \\
\hline Snow & $0.6-0.9$ \\
\hline
\end{tabular}

\section{THE HEAT LOSS}

This section examines in detail the heat losses caused by convection, radiation and evapolation.

\subsection{Convective Cooling $\left(\boldsymbol{P}_{\text {con }}\right)$}

The convective heat transfer per unit length per unit time, $P_{c o n}$ has three forms. Different types of convection can be calculated as follow $[8,9,10]$.

\subsubsection{Natural Convective cooling $(v=0)$}

$P_{\text {con }}=0.072 D^{0.75}\left(T_{S}-T_{a}\right)^{1.25}$

where $\mathrm{D}=$ conductor diameter (inch)

$\mathrm{T}_{\mathrm{s}}=$ Conductor temperature $\left({ }^{\circ} \mathrm{c}\right)$

$\mathrm{T}_{\mathrm{a}}=$ Ambient temperature $\left({ }^{\circ} \mathrm{c}\right)$

\subsubsection{Forced Convective cooling $(R e \leq 1000)$}

$P_{\text {con }}=\left[1.01+0.37\left(\frac{D P_{f} V}{U_{f}}\right)^{0.52}\right] K_{f} *\left(T_{S}-T_{a}\right)$

where $\mathrm{P}_{\mathrm{f}}=$ density of air $\left(\mathrm{lb} / \mathrm{ft}^{3}\right)$

$\mathrm{V}=$ wind velocity $(\mathrm{ft} / \mathrm{hr})$

$\mathrm{U}_{\mathrm{f}}=$ absolute viscosity of air

(lb/hr. ft)

$\mathrm{K}_{\mathrm{f}}=$ thermal conductivity of air,

(W/ft. $\left.{ }^{\circ} \mathrm{C}\right)$

\subsubsection{Forced Convective cooling $(R e \geq 1000)$}

$$
P_{\text {con }}=\left[0.1695\left(\frac{D P_{f} V}{U_{f}}\right)^{0.6}\right] K_{f} *\left(T_{S}-T_{a}\right)
$$

where $\quad \mathrm{P}_{\mathrm{f}}=$ density of air $\left(\mathrm{lb} / \mathrm{ft}^{3}\right)$

$\mathrm{V}=$ wind velocity $(\mathrm{ft} / \mathrm{hr})$

$\mathrm{U}_{\mathrm{f}}=$ absolute viscosity of air $(\mathrm{lb} / \mathrm{hr} . \mathrm{ft})$

$\mathrm{K}_{\mathrm{f}}=$ thermal conductivity of air, $\left(\mathrm{W} / \mathrm{ft} .{ }^{\circ} \mathrm{C}\right)$

The values of $P_{f}, U_{f}$ and $K_{f}$ can be determined from equations (9) - (11) and are useful for computer applications $[9,10]$ :

$$
\begin{aligned}
P_{f}= & 21.6578 e^{\text {elev }\left(-3.90696 \times 10^{-5}\right)} \times \\
& \times t_{f} \operatorname{lev}\left(1.51218 \times 10^{-7}\right)-0.996289\left(\mathrm{lb} / \mathrm{ft}^{3}\right)
\end{aligned}
$$




$$
\begin{aligned}
& U_{f}=\frac{t_{f}}{5165.9+5.16708 t_{f}}(\mathrm{lb} / \mathrm{h} \mathrm{ft}) \\
& K_{f}=1.20498 \times 10^{-3}+t_{f}\left(2.26545 \times 10^{-5}\right) \\
&\left(\mathrm{W} / \mathrm{ft}^{2}\right)
\end{aligned}
$$

where 'elev' is the elevation of the conductor above mean sea level (ft) and $t_{f}$ is the air film temperature.

\subsection{Radiation Cooling}

The heat loss due to radiation is approximated by [11]:

$P_{R} \cong \pi D_{S} \sigma_{B} \varepsilon\left\lfloor\left(T_{S}+273\right)^{4}-\left(T_{a}+273\right)^{4}\right\rfloor$

where, $\sigma_{B}$ is the Stefan-Boltzman constant, $T_{a}$ is the air temperature and $\varepsilon$ is the total emissivity of the surface of the conductor, and is given as

$\mathcal{\varepsilon}=\frac{\mathcal{E}_{s} \varepsilon_{x}}{\varepsilon_{x}+\varepsilon_{s}\left(1-\varepsilon_{x}\right) D_{s} / D_{x}}$

where, $\varepsilon_{s}$ is the emissivity of conductor surface having diameter $D_{s}$ and $\varepsilon_{x}$ is the emissivity of the surrounding distance $\mathrm{D}_{\mathrm{x}} / 2$.

So heat loss by radiation can also be written as:

$$
\begin{aligned}
P_{R}= & 0.17838 \times 10^{-6} * D_{S} \varepsilon_{S}\left[\left(T_{S}+273\right)^{4}-\right. \\
& -\left(T_{a}+273\right)^{4}
\end{aligned}
$$

\subsection{Evaporation Cooling}

When the conductor is wet, the evaporative heat loss $P_{w}$ is given by [1],

$$
P_{W} \cong P_{c o n}\left(p_{w s}-p_{w a}\right) / A_{c o n} p_{a}\left(T_{s}-T_{a}\right)
$$

Where

$$
\begin{aligned}
& \log _{10} p_{w s}=10.23255-1750.286\left(T_{s}+235\right)^{-1} \\
& p_{w a}=r\left(p_{w a}\right)_{s a t} / 100
\end{aligned}
$$

where $r$ is the percentage relative humidity, and $\left(p_{w a}\right)_{\text {sat }}$ is the saturated vapour pressure in the atmosphere, and is given by

$$
\begin{aligned}
\log _{10}\left(p_{w a}\right)_{s a t}= & 10.23255- \\
& -1750.286\left(T_{a}+235\right)^{-1}
\end{aligned}
$$

$A_{\text {con }}$ is the psychrometer coefficient that is equal to $5.8 \times 10^{-4} \mathrm{~K}^{-2}, p_{a}$ is the atmospheric pressure. The variation of the atmospheric pressure at altitude $H$ is given by

$$
p_{a}(H)=p_{a}(0)\left(1-6.5 \times 10^{-3} H / 288.16\right)^{5.2561}
$$

\section{TIME-CONDUCTOR TEMPERATURE CALCULATION}

When the conductor current is increased, the conductor temperature will also be increased by the impressed current, the conductor properties and ambient conditions. When conductor current has changed, the steady state condition for heat equation is no longer balanced. It is because the resistive heat gain has increased instantaneously. Resistive heat gain can be written as an additional heat term $\Delta P$ in the heat equation. This additional heat input raises the conductor temperature over time until it reaches a new value such that the heat equation is in balance again. The heat equation can be written as follows [12]:

$$
\begin{aligned}
& P_{i n}=P_{\text {out }}+\Delta P \\
& P_{\text {in }}=I^{2} \times R_{a c}+P_{S}+P_{m} \\
& P_{\text {out }}=P_{C}+P_{r}+P_{W}
\end{aligned}
$$

Assuming for a short time interval, where $\Delta t$ is less than 10 seconds. Over this period, the conductor temperature is increasing by $\Delta T$. The increase of conductor temperature provided by excessive energy can be expressed as follows [12]:

$\Delta P \times \Delta t=m \times s \times \Delta T$

Rearranging the above equation, we get

$\Delta T=\Delta P \times \Delta t /(m \times s)$

A new conductor temperature, resulting from heat storage during the increment can be calculated as:

$T_{\text {new }}=T_{\text {old }}+\Delta T$

$T_{\text {new }}$ now can be calculated and used to compute $\Delta T$ corresponding to the next time interval $\Delta t$. The process continues until the entire rating period is calculated. Final calculated temperature can then be compared with the allowable conductor temperature.

\section{PRACTICAL APPLICATION}

A $110 \mathrm{kV}$ power transmission line (copper 19/0.116", 19 strands), was used with the load current increased from 244A to 449A [13]. Under steady condition of wind velocity and ambient temperature, different thermal rating can be imposed on to this transmission line depending on the cloud condition.

Fig 1 shows that the cloud condition which affect the loading capabilities of power transmission line. From Table 2, under clear sky condition $(c=0)$, it shows that it only took 0.4 minute for the conductor to reach its maximum temperature with steady state rating of $261 \mathrm{~A}$. Under cloudy conditions $(c=0.7)$, it took about 5 times longer (2.1 minute) to reach maximum temperature. The steady state rating also increases by approximately $20 \%$ (316A). However in very cloudy condition $(c=1)$, it took up to 12 times longer compared to clear sky condition (4.8 minute) to reach the maximum temperature and the steady state rating increases by approximately $40 \%$ (368A). In other words, the overload can last up to 4.8 minutes. This shows that overload can last longer under very cloudy sky condition compared to clear sky condition. 


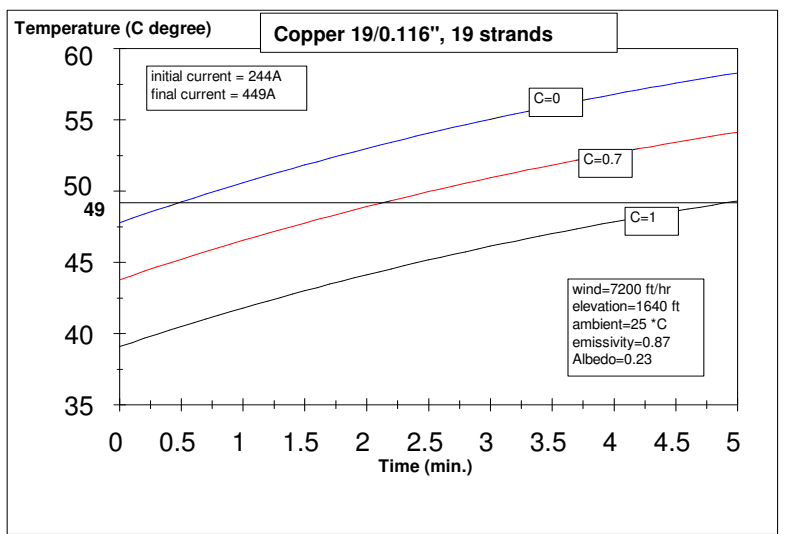

Fig. 1 Temperature Vs Time under different cloud condition.

Table 2: Results obtain under different cloudy factor (Albedo $=0.23$ )

\begin{tabular}{|l|c|c|c|}
\hline \multicolumn{1}{|c|}{ Remarks } & $\mathrm{C}=0$ & $\mathrm{C}=.7$ & $\mathrm{C}=1$ \\
\hline Max. design temp. $\left({ }^{\circ} \mathrm{C}\right)$ & 49 & 49 & 49 \\
Initial temp. $\left({ }^{\circ} \mathrm{C}\right)$ & 47.8 & 43.8 & 39.1 \\
Steady state rating (A) & 261 & 316 & 368 \\
Time to reach $49^{\circ} \mathrm{C}(\mathrm{min})$ & 0.4 & 2.1 & 4.8 \\
\hline
\end{tabular}

Fig. 2 and Table 3 show the results obtained under different operating hours at the same conditions as above. Fig. 2 shows that during midday, when solar heat gained by conductor is maximum, lowest values of thermal rating and overload duration were obtained. It took only 2.1 minutes to reach the maximum temperature in the midday with steady state rating of $316 \mathrm{~A}$, and 1.5 times longer ( 3.3 minutes) in the morning with steady state rating increase by approximately $10 \%$ (346A). However, it took 4.5 minutes, which was almost double the time compared to the midday condition to reach maximum temperature in the evening with steady state rating increase by approximately $15 \%$ (364A). So, this clearly tells us that solar heat gain affects the loading capabilities of power transmission line.

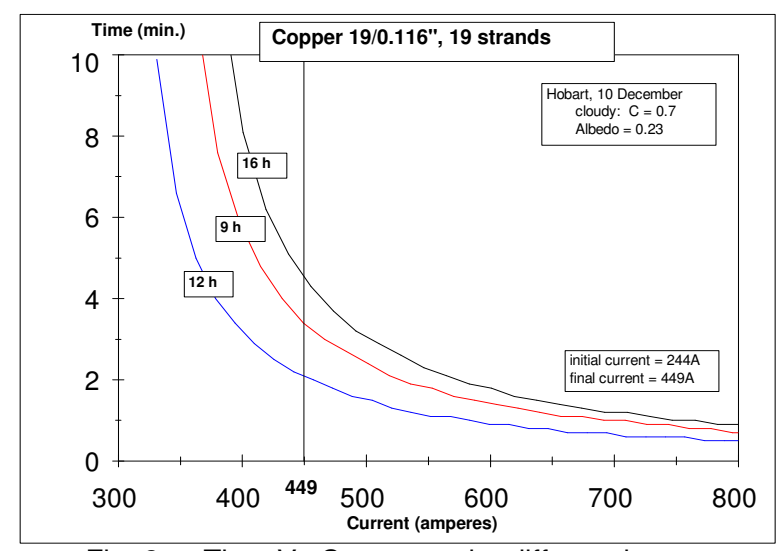

Fig. 2 Time Vs Current under different hours.

Table 3: Results obtain under different hours. (Albedo $=0.23, \mathrm{C}=0.7$ )

\begin{tabular}{|l|c|c|c|}
\hline \multicolumn{1}{|c|}{ Remarks } & $9 \mathrm{~h}$ & $12 \mathrm{~h}$ & $16 \mathrm{~h}$ \\
\hline Max. design temp. $\left({ }^{\circ} \mathrm{C}\right)$ & 49 & 49 & 49 \\
Initial temp. $\left({ }^{\circ} \mathrm{C}\right)$ & 41.2 & 43.8 & 39.5 \\
Steady state rating (A) & 346 & 316 & 364 \\
Time to reach $49^{\circ} \mathrm{C}(\mathrm{min})$ & 3.3 & 2.1 & 4.5 \\
\hline
\end{tabular}

Heat equation has been studied in detail in this paper. From sample particle application, it shows that the loading capabilities of a transmission line will be affected by the surrounding atmosphere conditions, such as the sky condition and the position of sun. Under very cloudy sky condition, the overload can last about 12 times longer compared to the clear sky condition. Also in the evening, conductor overload duration can last up to twice the time compared to the midday.

\section{List Of Symbols}

I current, (A)

$m \quad$ mass per unit length of conductor, $(\mathrm{kg} / \mathrm{ft})$

$H$ altitude of the sum (angular elevation above horizon).

D overall diameter of conductor, (m)

$d \quad$ outer wire diameter of conductor, $(\mathrm{m})$

$s \quad$ specific heat at constant pressure. (J/kg. Deg.C)

$P_{J} \quad$ power gain per unit length by joule heating, (W/ft)

$P_{M} \quad$ power gain per unit length by magnatic heating, (W/ft)

$P_{S} \quad$ power gain per unit length by sollar irradiation, $(\mathrm{W} / \mathrm{ft})$

$P_{c o n}$ power loss per unit length by forced convection, (W/ft)

$P_{w} \quad$ power loss per unit length by evaporation, (W/ft)

$P_{R} \quad$ power loss per unit length by radiation, $(\mathrm{W} / \mathrm{ft})$

$R_{d c} \quad$ d.c. resistance per unit length, $(\Omega / \mathrm{ft})$

$P_{f} \quad$ Density of air $\left(\mathrm{lb} / \mathrm{ft}^{3}\right)$

$U_{f} \quad$ Absolute viscosity of air $(\mathrm{lb} / \mathrm{hr} . \mathrm{ft})$

$K_{f} \quad$ Thermal conductivity of air (W/ft. ${ }^{\circ} \mathrm{C}$

$\mathrm{T}_{\mathrm{a}} \quad$ air temperature, $\left({ }^{\circ} \mathrm{C}\right)$

$\mathrm{T}_{\mathrm{s}} \quad$ mean temperature of conductor surface, $\left({ }^{\circ} \mathrm{C}\right)$

$v \quad$ wind velocity, $(\mathrm{m} / \mathrm{sec})$

$\alpha_{0} \quad$ temperature coefficient of resistance, per deg.C

$\varepsilon_{\mathrm{s}} \quad$ Surface emmissivity

$\lambda$ effective radial thermal conductivity of conductor, (W/m. deg.C)

$\sigma \quad$ Stefan-Boltzmann constant $=5.64 \times 10^{-8} \mathrm{~W} / \mathrm{m}^{2}$

$\mathrm{F} \quad$ albedo of ground

$\mathrm{r}$ percentage relative humidity

$\mathrm{A}_{\text {con }} 5.8 \times 10^{-4}\left(\mathrm{~K}^{-2}\right)$

$\mathrm{P}_{\mathrm{a}} \quad$ Atmospheric pressure

\section{REFERENCES}

1 V.T. Morgan, "The thermal rating of overhead-line conductors, Part II. A sensitivity analysis of the parameters in the steady-state thermal model", Electr. Power Syst. Res. 6 (1983) 287-300.

2 V.T. Morgan and R. Morrow, "Cooling of a heated cylinder in still air by electrical corona", Inst. Eng. Aust. Electr. Eng. Trans., EE16(1980)-15 
3 V.T. Morgan, "Thermal Behaviour of electrical conductors", 1991 pp455-457.

4 V.T. Morgan, "Thermal Behaviour of electrical conductors", 1991 pp73-77.

5 V.T. Morgan and C.F. Price (1969) "magnetic properties in axial $50 \mathrm{~Hz}$ fields of steel core wire for overhead line conductors". Proc. IEE 116 16811694.

6 "Current rating of bare overhead line conductors", Electricity Supply Assosiation of Australia. No.D(b)5 1988.

7 V.T. Morgan, "The current carrying capacity of bare overhead conductors", inst Eng. Aust, Electrical Engineering Trans,. 1968, pp. 63-72.

8 H.E. House and P.D. Tuttle,. "Current carrying capacity of ACSR", AIEE Trans. PAS, Vol. 77, Feb. 1959, pp. 1169-1177.

9 T.L. Le, M. Negnevitsky and M. Piekutowski, "Expert system application for the loading capability assesment of transmission lines", IEEE Trans. on Power System, Vol. 10, No. 4, Nov 1995, pp. 1805-1812.

10 H.A. Smolleck and J.P., Sims, "Guidelines for the selection and operation of bare ACSR conductors with regard to current carrying capacity", EPSR, 5. 1982, pp. 179-190.

11 V.T. Morgan, "The thermal rating of overhead-line conductors, Part I - The steady-state thermal model”. Electr. Power Syst. Res. 5 (1982) 119-139.

12 F. Vakili, and M.R. Viles, "Dynamic thermal line loading monitor", IEEE Trans. on Power System, Vol. PWRS-1, No.2, May 1986, pp. 62-66

13 T.L.Le, and M. Negnevitsky, "An intelligent system for short-time loading capability assessment of transmission lines", proceedings of the $8^{\text {th }}$ international conference on zintelligent system application to power system, ISAP-96, Florida, USA, Jan 1996, pp. 80-84. 